\title{
Impact of social media on tourism education
}

\author{
Rojanard Waramontri ${ }^{1, *}$ \\ ${ }^{1}$ International College, Suan Sunandha Rajabhat University, Bangkok, Thailand
}

\begin{abstract}
The essence of social media is growing rapidly in the tourism industry. More and more researchers are working on investigations in the areas of the impact of social media on many aspects of the tourism industry. Social media plays a significant role to develop strategy for tourism management. Therefore, this research based on the knowledge to support education in tourism management. The main objective of the paper is 1 . To investigate the relationship between social media and tourism. 2 . To examine the positive and negative impact of social media in tourism industry. Through a comprehensive literature review, this paper identifies information search and decision-making behaviors which is relevant to social media in tourism, and recommends the best use of social media for tourism.
\end{abstract}

\section{Introduction}

This paper is created by the motive on contents about the impact of social media and the tourism sector. In the past, social media has gradually changed the way organizations communicate with their customers. Social media sites in the internet today are mostly used. It is recognized and preferably more than the physical participation of individuals in the correspondence. Some of the favoured social media sites are the Facebook, Instagram and YouTube. It is vital to note that the intercourse in the virtual world are super speedy. Moreover, this way of transmission is the fastest way of spreading news comparing with any other form of contact over the internet. Before, it is the power of word of mouth. Nowadays,it's the e word of mouth which is the word of mouth through the social media sites. This channel made it easy for the world to be able to get references. This makes customers to make choices easier and it also supports the process of decision making of customers as to which is the best offer for the customers. For example, the customers are able to choose particular destination, the customers are able to choose the best accommodations.

According to [1] mentioned that power of persuasiveness is more influential than share voice especially when it reached the point to assess the power of the connoisseur on the decision maker. As a result, organizations can increase customer satisfaction and profitability by applying social media.

However, the reach of comments on social networks can sometimes be double edged sword. In addition, social media connoisseurs on Instagram apply their sharing and promotional power which will benefit the tourism industry by increasing number of tourists

${ }^{*}$ Corresponding author: rojanard.wa@ssru.ac.th 
rapidly. But in the negative side of tourism industry, it leads to over tourism. Consequently, social media campaigns bounced back according to issues or environmental incidents. For instance, going on somewhere in the world and tourism providers posting something that could be considered as abusive or obnoxious.

As a result, the dark side of social media appear in the form of consumer complaints. It is suggested for marketers worldwide to be aware of how social media can recoil in tourism. Many tourism providers worldwide pinpoint the essence of social media for their organization and are actively engaging on a range of social media channels.

However, there are many contents about discussion of social media campaign rebounding. There are not much case study about consumers' reactions that reviewed as repellent towards things tourism providers are stating on social media channels. The possible dark side of tourism is about organizations being in trouble over things they have said. Therefore, this research is aimed to investigate the relationship between social media and tourism and to examine the positive and negative impact of social media in tourism industry.

\section{Methodology of the study}

Social Media and its relationship with the education in tourism industry has been verified and discussed by many researchers across the world. A qualitative analysis of literature has been conducted accompany with essential definitions and aspects of various works about Social Media. The focus of the study is to establish a working relationship between Social Media and tourism. Studies, surveys, and concepts discussed by researchers have been analyzed. The discussion in the context of various Social Media factors that influence tourism will guide the reader to the balance use of social media to minimize negative impact of social media. Then, the researcher led to suggestions for future research.

\section{Literature Review}

The term social media apprehend and use as Internet-based applications. The benefits of this are the consumer-generated content which get the picture of a higher level of social interaction among customers. From customer's viewpoint, the value of using social media came from the intense on personal experiences. The essence of trustworthiness that transformed in the form of electronic word-of-mouth. There are many ways being brought to collect data from research papers and studies to achieve the awareness of the relationship between social media and tourism management education. One of the methods was Google scholar search engine which guided the researcher on research papers and literature on keywords like - social media, tourism. Moreover, a number of articles that defined the impacts and use of social media in tourism education were collected.

\subsection{Relationship between Social Media and Tourism}

As above mentioned, social media requires all marketing activities integration and uses persuasive advertising to provide outstanding experiences about the services. The electronic word of mouth is essential for marketers to find out this new scaffold for conversation. This is another tactic which most suitable to support customer relationship. The electronic Word of Mouth can enhance visitor satisfaction due to product or service development. Furthermore, eWOM can be one of the best solutions to solve problems in many parts of travel industry management. For instance, this can help customers to discover what others think and state about their experience. However, the main advantage can be monitoring of 
the company's image. Another benefit can also be the way for service provider to update the competitive strategies.

For example, the marketers are able to analyze the levels of customers satisfaction. The impact of user generated content by social media affects a travellers' decision making. A number of studies have also revealed the impact of social media on travellers' information search behaviour. The suggestion identified that travel reviews on social media sites help add fun to the planning process of the customers.

Furthermore, it works in the way by increasing confidence in individual especially for travellers' decision to reduce risk of the unknown or uncertainty. According to [2], social media helps satisfied customers. Moreover, the power came from the way to voice the customers' opinion to millions of people with the emphasis on positive reviews. This has been recognized as the "best advertisement money can buy". [3] reported that $82 \%$ of US customers who go online search for reviews from travel sites in relations to traveller's decision-making process. However, reviews on sites such as Facebook offers a star rating based on the whole experience. Furthermore, organizations need to analyze the words customers used [4]. Besides, attracting or detracting an individual, online reviews provide knowledge so they can picture their destination [5].

Studies [6-9] suggest companies that engage with social media encourage long-term relationships with existing and new customer.

Some scholars $[1,10]$ have mentioned Television traditionally had the largest share in paid advertising. However, digital advertising spending surpassed it in 2017.Besides, Word of mouth (WOM) are also a major influence to attract tourist [5]. Traditional Word of Mouth (WOM) has become E WOM. Therefore, influencer marketing has emerged. Furthermore, the advertising focuses on specific individuals with a large number of followers of their destinations is a form of marketing.

In addition, it is "the art and science of engaging people who are influential online to share brand messaging with their onlookers in the form of sponsored content" [11]. Because social media is low-cost and bias-free, it represents an advantage for marketing communications. It can be noticing that, there are various ways to save cost. This might conclude to other reason of using social media as a marketing tool is that it provides a less expensive approach to marketing a tourism destination.

Nowadays, travelers' don't trust ads that focuses on qualities and indication of destination. Instead, they require creative message with an intelligence and a personal touch. Because the experiences include warmth and appreciation, the marketing tool applies participation as the social media marketing. This marketing tool is to ensure that thepresence on social media is always available whenever potential travellers' search for a similar information in the tourism.

Research shows that organizations that engage with customers who post online reviews leads to expansion of customer satisfaction [12] and competitive advantage [13, 14]. This is a common approach used by many service providers. For example, the reviews will show the remaining hotel rooms on TripAdvisor.

The benefit of customers' engagement is to operate revenue from booking platforms which leads to higher customer turnover [15]. Studies (16-20] suggest that eWOM and reviews have trickle effects on customers booking decision. The large number of positive reviews impacts on the customer's decision to book a room [16]. Furthermore, when managers respond to negative reviews with facts and brand principle, consequently, it shows in the esteems of customer decision [21].

Social media and social networking sites act as major marketing tools and enforce many areas. These tools generally provide the platform to the users to achieve guidance about product and services. Also, the customers are able to build their awareness, share their thoughts, travel experiences and travel reckoning. Likewise, the benefits for companies is 
by providing an opportunity to market their destination, augment brand loyalty and to enrich long term relationships [9]. The use of social media as a marketing tool is truly valuable because it provides competitive advantages to organizations over their competitors.

\subsection{Impact of Social Media in Tourism}

Facebook in particular has a great effect over consumer choices especially in the travel sector. The data of [22] conducted in 2012 has shown that over $90 \%$ of consumers from all over the world say they trust and believe recommendations from friends such as word-ofmouth,Moreover, the potential customer will be influenced by the comments and statements on social media.As a result, the image of the tourism depend on these comments.

Table 1. Research on social media impact on tourism.

\begin{tabular}{|c|c|l|}
\hline Scholars/Year & Topic & \multicolumn{1}{c|}{ Results } \\
Kastenholz (2011) & $\begin{array}{c}\text { Social media impact on } \\
\text { tourism marketing }\end{array}$ & $\begin{array}{l}\text { Research shows that organizations that enlist } \\
\text { with customers who post online review leads to } \\
\text { upsurge customer loyalty. }\end{array}$ \\
\hline Abdullah(2012) & $\begin{array}{c}\text { Internal Success Factor of } \\
\text { Hotel Occupancy Rate }\end{array}$ & $\begin{array}{l}\text { Research shows that social media helps to } \\
\text { satisfy customers. }\end{array}$ \\
\hline Leung(2013) & $\begin{array}{c}\text { Social media in tourism } \\
\text { andhospitality }\end{array}$ & $\begin{array}{l}\text { Research shows that organizations that enroll } \\
\text { with customers who post online reviews } \\
\text { expand customer turnover. }\end{array}$ \\
\hline Serlen (2010) & $\begin{array}{c}\text { Hilton cultivates social } \\
\text { media across its brands }\end{array}$ & $\begin{array}{l}\text { Research shows that organizations that appoint } \\
\text { customers who post online reviews leads to } \\
\text { raisecompetitive advantage }\end{array}$ \\
\hline Browning (2011) & $\begin{array}{c}\text { The impact of online } \\
\text { reviews on hotel booking } \\
\text { in intentions and } \\
\text { perceptions of trust }\end{array}$ & $\begin{array}{l}\text { Studies suggest that eWOM and reviews have } \\
\text { an exuding impact on customers booking } \\
\text { decision. A majority of positive reviews } \\
\text { influences the customer's decision to book a } \\
\text { room. }\end{array}$ \\
\hline Sashi (2012) & $\begin{array}{c}\text { Customer engagement, } \\
\text { buyer-seller relationships, } \\
\text { and social media, } \\
\text { Management Decision }\end{array}$ & $\begin{array}{l}\text { He believes that organizations that engage with } \\
\text { social media forge long-term relationships with } \\
\text { existing and new customers. }\end{array}$ \\
\hline
\end{tabular}

Therefore, social media influence the travel in various aspects. While the positive statements will include the good experience and satisfaction of the customers, negative comments will include disappointments and bad experiences. So, it is very important to analyze the effect of negative comments as the example of destination image and traveller decisions. Social media has a big impact on travel decisions. Furthermore, the potential customer will be connected with the comments and statements on social media in tourism industry.

From table 1, revealed that the social media contents are easily accessible and very influential. Social media also strike the customer services which led to customer satisfaction. Presence on social media assist the marketers to address the complaints and problems of customers. In addition, this will result to set up a strong reputation among current and future customers.

Moreover, responding to customers complaints helps companies to have bonding among customers and their brand.This is the heart of customer service. One of the technic is to emphasize that customers are valued and it is a way to enhance customers'perception. 
Furthermore,this format of social mediaclassified as a single piece of content becomes a topic of interaction between multiple users.

However, if the social interactions are negative which express in the social media interactions like likes, shares, comments, this will result in negative interaction. This negative information will not spread only to followers, but also the potential customers.Thus, socialmediahavea“calledeffect"overareas of travel sectors in tourism management. The result grant to overcrowding and subsidize over tourism. Thus, adopting a thoughtful long-term planning strategy with a multi-action and multi-stakeholder approach to address over tourism seems to be the right way to address this issue [23]. Over tourism spoils the good economic.

Furthermore, this causes reductions in the quality of service of the tourist destination and possibilities of rejection from the local people. Previous literature has suggested that the use of social media could beacceleratorsoftheprocessofovercrowding. Therefore, the researcher suggested for marketers to maintain an ethical code of management in their marketing perspectives.

Ethical code of management simply means that marketers should not provide misleading instruction and incorrect advertisement content.Furthermore, it is very important to address the customers' complaints because it will create positive image regarding responsiveness of company. Finally, it is important for marketers to resolve their problem byaccessingthe customers' feedback to check the latest commentsin order to increase positive impacts and to minimize negative impacts.

\section{Results and discussion}

From the scrutiny of the previous scholars, the researcher recommends an important tool called Ethical code for tourism management to access social media in the organization's site. In addition, this is the good opportunity for the marketers to check the latest comments to surge positive impacts and to lessen negative impacts. This is very important in many functions in the travel sectors. Furthermore, the researchers see the needs to be addressed in organizations worldwide. It is obvious that positive comments and consumers alluring with organization's content is pleasant.

However, negative comments will happen at some points. Once the negative comments occur, these need to be dealt with appropriately. The management will sustain the success of an organization on social media. This is similar to the recommendations of [7] believes that customer engagement takes different behavioral forms. Furthermore, the author suggests that user-generated hotel comments can have a positive or negative impact on business influence [24]. So, the management of customer engagement should respond in the specific way instead of generic way. The researcher suggests the organizations to think about plans, guidelines and strategies to be updated to current situations. Since negative comments are coming in, it might be too late to think about how to handle these incidents. In order to curtail damage to the company's reputation and brand, the organization should establish department of ethical social media management team. Social media campaigns need to be monitored closely by the tourism providers in order to ensure they run smoothly.

As mentioned above, organizations seek to manage the problems of over tourism; the ideas established in this paper resolve the impact of social media by offering useful applied guidelines for limiting over tourism. They are devised from the recommendations of successful ethical code for tourists. Being labelled as ethical-social media management department is acceptable department of appreciation for organization in the tourism management. Social media management is the tool which introduced limitations, closures and much more as a precaution against the incidents of over-tourism. In tourism management education, it is widely acceptable to find the best use of social media. The 
researcher did find key areas that identify the balance between the needs of tourists, locals and the environment. It is in the appreciation of many stakeholders and in the spirit of the Tourism Management Education to encourage the strategies and tools.

\section{Conclusions}

In summarization, it can be concluded that Tourism Industry is an important source of revenue for many countries. Tourism Management is also the valuable resources for employment. However, due to changing environment, technology became the vital marketing tools in the tourism management education.

Therefore, media advancements is essential for marketers to adapt their strategies in various areas as communication strategies and management strategies. The focus of ethics and the way service providers promote themselves via social media in the market is vital. Adoption of ethical social media management and new social media strategies are crucial for the survival of organizations. Nowadays customers don't believe advertisements that basically focus on features and benefits of the products or services. Customers made decision based on relationships. Social media assist the marketers to provide interesting content. Besides, the double edged sword of social media verified the positive benefits and negative impacts of social media.

The dark side of social media may give bad input to the image of tourism industry in long term. In addition. Social media may grant to over tourism. But these negative impacts can be diminished if the marketers will globally address the problems of customers. The adaptation of management strategic or department to handle the negative impacts were introduced to organization in tourism.

Given the exploratory nature of this study, more research is needed to better explain the resolutions of over tourism. Future research will address the discussions of the causes and effects from the use social media in order to confirm the best use of social media. The confirm results then leads to the approach to tourism management. Then, the best current conceptual are recommended for tourism education.

\section{References}

1. S. Woods, University of Tennesse Honors Thesis Projects (2016)

2. A. Abdullah, M.H. Hamdan, Int. J. Bus. So Scien. 22, 199-18 (2012)

3. A. Privara, Transnational Marketing Journal 7(1), 59-72 (2019)

4. Z. Xiang, I. Tussyadiah, Baggio M. Sigala, Information and Communication Technologies in Tourism (2014)

5. K. Manap, N. Adzharud, The role of User Generated Content(UGC) in Social Media for Tourism Sector 52-8 (2013)

6. C. Sashi, Management Decision 50, 253-72 (2012)

7. W. Wei, L. Miao, Z. Huang, Int. J. Hosp. mgmt. 33, 316-30 (2013)

8. F. Cabiddu, M. DeCarlo, G. Piccoli, Anals Tm. Res. 48, 175-92 (2014)

9. P. Chathoth et al., T.M. 42, 181-93 (2014)

10. A. Privara, Migration Letters 16(2), 245-254 (2019)

11. K. Sammis et al., Influencer Marketing for Dummies (New Jersey, John Wiley \& Sons, 2016)

12. K. Sano, H. Sano, PAMS 86-8 (2016) 
13. B. Serlen, H. Bus 16, 4 (2010)

14. Alsobhi Abeysinghe, Impact of Social Media readiness on Social Media Usage and Competitive Advantage (IGI Global, 2013)

15. D. Leung et al., J. Travel Tour. Mark 30, 3-22 (2013)

16. B. Sparks, V. Browning, T.M. 326, 1310-23 (2011)

17. Q. Ye et al., Computers in Human Behavior 27(2), 634-39 (2011)

18. B. Guillet, R. Law, Int. J. Cont. Hosp. M. 22, 797-13 (2011)

19. N. Simasathiansophon, The EUrASEANs: Journal on Global Socio-Economic Dynamics 3(22), 66-71 (2020)

20. R. Ladhari, M. Michaud, Int. J. Hosp. M. 46, 36-5 (2015)

21. S. Park, J. Allen, Cor. Hosp. Q. 54, 64-3 (2013)

22. I. Pavlenko, The EUrASEANs: Journal on Global Socio-Economic Dynamics 6(7), 92101 (2017)

23. K. Koens, A. Postma, B. Papp, Sustainability 10, 4384 (2018)

24. A. Privara, M. Privarova, Sustainability 11, 5586 (2019) 